\title{
LEFT VENTRICULAR ANEURYSM IN A BANTU CHILD
}

\author{
BY
}

\author{
A. DUBB, G. KATZ, AND M. BERK
}

From the Cardiac Clinic, Johannesburg General Hospital and C.S.I.R. Cardio-Pulmonary Research Unit, Departments of Medicine, Thoracic Surgery and Radiology, University of the Witwatersrand, Johannesburg, South Africa

Ventricular aneurysms due to causes other than coronary artery disease are uncommon. We report here an instance of an acquired left ventricular aneurysm in a Bantu girl. The aneurysm was of uncertain ætiology and was surgically repaired.

\section{Case Report}

The 12-year-old patient stated that she had been completely well until five months before her visit to this Clinic on January 29, 1963. At that time her ankle and elbow joints had become painful and swollen. A few days later she developed sudden severe præcordial pain which lasted about 12 hours and was associated with sweating and breathlessness. She was admitted to another hospital where her sedimentation rate was found to be raised ( $31 \mathrm{~mm}$./hour, Wintrobe) and a diagnosis of rheumatic fever was made. The polyarthritis and chest pain improved on penicillin, salicylate, and corticosteroid therapy. She was referred to this clinic for an assessment of her cardiac condition.

Examination revealed a well-nourished Bantu girl with a somewhat "moon-face" due to the steroid therapy. The only other abnormal findings were in the cardiovascular system. Her pulse rate was 75 a minute, regular, and of normal volume. Her blood pressure was $120 / 70 \mathrm{~mm}$. Hg. The jugular venous pulsations were normal. The apex beat was displaced to the sixth intercostal space just outside the midclavicular line and was left ventricular in type. No abnormal impulses were detected in the region of the cardiac apex. On auscultation a very short, loud and musical systolic murmur was heard near the apex (Fig. 1). This murmur increased in intensity when the patient lay on her left side but varied considerably with respiration and was best heard during held mid-inspiration. A systolic click sometimes occurred in the middle of this short systolic murmur. A short but moderately loud early diastolic murmur was present at the sternal border. The second heart sound was normal.

The electrocardiogram showed an axis of $+20^{\circ}$. T wave inversion was present in all the præcordial leads but there was no evidence of ventricular hypertrophy. A postero-anterior teleradiogram indicated slight cardiomegaly (cardio-thoracic ratio of $53 \%$ ) and a rounded protruberance in the region of the apex of the

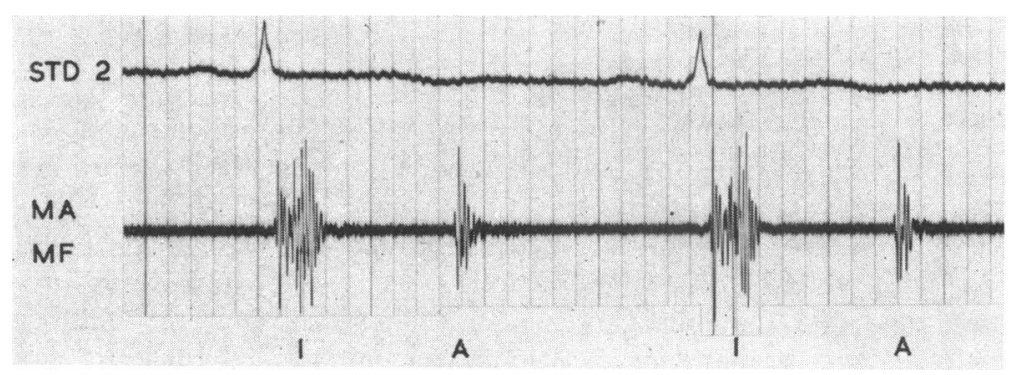

FIG. 1.-Phonocardiogram recorded in held mid-inspiration. The short crescendo-decrescendo systolic murmur is clearly shown. Time between heavy vertical lines is 0.2 second. MA, mitral area; MF medium frequency; 1, mitral component of first heart sound; A, aortic component of second heart sound. 


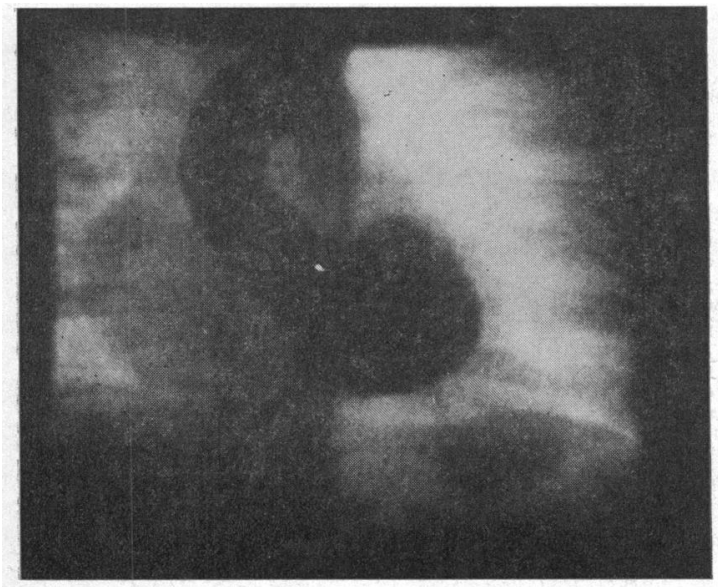

(A)

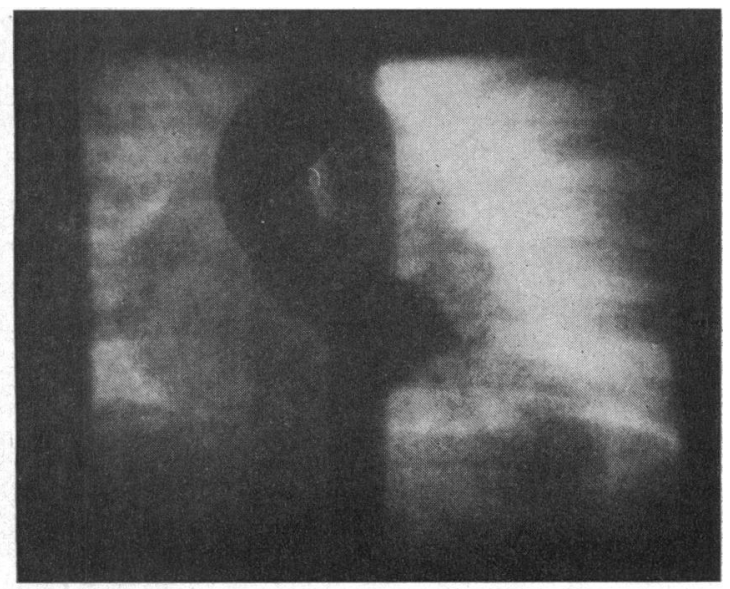

(B)

FIG. 2.-Frames from cine-angiogram during (A) early systole and (B) late systole. The saccular aneurysm is seen behind the left diaphragm.

left ventricle. The Wassermann reaction was negative and there was no evidence of toxoplasmosis on the complement-fixation reaction or Sabin-Feldman dye test.

On February 12, 1963, a left ventricular cineangiocardiogram, performed by the retrograde Seldinger technique, demonstrated the passage of dye during early systole through a narrow neck into a saccular aneurysm at the apex of the heart (Fig. $2 \mathrm{~A}$ and $\mathrm{B}$ ).

On April 1, 1963, the patient was operated on by one of us (G.K.) through a median sternotomy incision. The pericardial sac was obliterated by thin avascular adhesions. These were freed except in the region of the aneurysm. Cardiopulmonary bypass with a disc oxygenator was established, using a single atrial drain and left femoral artery cannulation. The aneurysmal sac was then safely mobilized. It was intimately adherent to the pericardium and arose from the apex of the left ventricle. The globular aneurysm, approximately two inches in diameter, had a thin and fibrous wall. The pericardium was intact. A systolic thrill was palpable at the neck of the sac. The muscular neck of the aneurysm was clamped and the sac excised.

The post-operative course was uneventful, except for a short period of pyrexia and a painful swollen knee five weeks after the operation. The heart sounds became normal and the $T$ waves became upright in the left chest leads.

Histopathology of the Specimen (Dr. S. Siew). Cardiac muscle was present only in the neck of the aneurysm. The wall consisted largely of dense fibrous tissue. There was well-marked endarteritis, periarteritis (predominantly of lymphocytes and plasma cells), and concentric peri-arterial fibrosis. These findings indicated a non-specific inflammatory reaction.

\section{Discussion}

Atiology. Left ventricular aneurysms, other than those complicating atherosclerotic myocardial infarction, are rare (Parkinson, Bedford, and Thomson, 1938; Abrahams et al., 1962). Previously reported causes are: syphilis (Braunstein, Bass, and Thomas, 1940; Jacobs, 1952), mycotic infections (Pirani, 1943), rheumatic myocardial necrosis (Parkinson et al., 1938), trauma (Pitts and Purvis, 1947), tuberculosis (Beheyt and Joris, 1963), anomalous origin of coronary arteries (Sanes and Kenny, 1934), malarial endarteritis (Macfie and Ingram, 1920), congenital lesions (Clearkin and Bunjé, 1955; Abrahams et al., 1962), and unidentified causes (Zeeman et al., 1962; Schrire and Barnard, 1963).

The ætiology in our case remains obscure. Though the pathological description is similar to the cases described by Abrahams et al. (1962) in Nigerian Africans, the site is different, namely the apex of the ventricle and not the atrio-ventricular groove. 
Auscultatory Findings. Although murmurs have been considered to be of little diagnostic value in cardiac aneurysm (Dressler and Pfeiffer, 1940; Fulton, 1941), they were impressive and unusual in our case. The short ejection systolic murmur was almost certainly produced by the flow of blood into the aneurysm in very early systole. It is probable that ventricular muscle contraction completely occluded the narrow neck during the later major part of systole. The early diastolic murmur presumably resulted from the return of blood into the left ventricle during diastole. An apical systolic click has also been described by Levine and Harvey (1959) who postulate that it may be produced by the paradoxical systolic expansion of the aneurysm striking against the chest wall.

\section{Summary}

The successful removal of a left ventricular aneurysm is reported in a 12-year-old Bantu girl. Unusual auscultatory features were present and their mechanisms are briefly discussed. The aneurysm occurred at the apex of the heart; its ætiology remains uncertain.

Thanks are due to Dr. John Barlow for his encouragement, advice, and criticism, and to the medical and nursing staff of the Non-European General Hospital, Johannesburg, for their care of the patient. We are grateful to Dr. K. F. Mills, Superintendent of the Johannesburg Group of Hospitals, for permission to publish.

\section{References}

Abrahams, D. G., Barton, C. J., Cockshott, W. P., Edington, G. M., and Weaver, E. J. M. (1962). Annular subvalvular left ventricular aneurysms. Quart. J. Med., 31, 345.

Beheyt, P., and Joris, H. (1963). L'anévrisme ventriculaire gauche chez le jeune Africain. Acta cardiol. (Brux.), 18,113

Braunstein, A. L., Bass, J. B., and Thomas, S. (1940). Gummatous myocarditis and aneurysm of the left ventricle, with nodal tachycardia, and, subsequently, bundle branch block; Report of case. Amer. Heart J., 19, 613.

Clearkin, K. P., and Bunjé, H. (1955). Rare cardiac aneurysm in a young adult. Thorax, 10, 42.

Dressler, W.; and Pfeiffer, R. (1940). Cardiac aneurysm; A report of 10 cases. Ann. intern. Med., 14, 100.

Fulton, M. N. (1941). Aneurysm of the ventricle of the heart. J. Amer. med. Ass., 116, 115.

Jacobs, H. D. (1952). Cardiac aneurysm. M.D. Thesis, University of Witwatersrand.

Levine, S. A., and Harvey, W. P. (1959). Clinical Auscultation of the Heart, 2nd ed., p. 601. Saunders, Philadelphia.

Macfie, J. W. S., and Ingram, A. (1920). Three cases of cardiac aneurysm in native boys of the Gold Coast. Ann. trop. Med. Parasit., 14, 147.

Parkinson, J., Bedford, D. E., and Thomson, W. A. R. (1938). Cardiac aneurysm. Quart. J. Med., 7, 455.

Pirani, C. L. (1943). Erosive (mycotic) aneurysm of the heart with rupture. Arch. Path., 36, 579.

Pitts, H. H., and Purvis, G. S. (1947). Ruptured traumatic cardiac aneurysm in a child. Canad. med. Ass. J., 57, 165.

Sanes, S., and Kenny, F. E. (1934). Anomalous origin of left coronary artery from pulmonary artery, with myocardial fibrosis of left ventricle and partial aneurysm at the apex. Amer. J. Dis. Child., 48, 113.

Schrire, V., and Barnard, C. N. (1963). The surgical cure of a cardiac aneurysm of unknown cause. J. cardiovasc. Surg. (Torino), 4, 5.

Zeeman, S. E., Templeton, J. Y., Goldburgh, W. P., and Aponte, G. (1962). Ventricular aneurysm. Report of a case occurring in a 16-year-old boy with granulomatous myocarditis. Amer. Heart J., 63, 270. 